\title{
MOTHERS KNOWLEDGE RELATED PREVENTIVE MEASURE OF PNEUMONIA IN SLUM COMMUNITY, KARACHI, PAKISTAN
}

\author{
Adeel Eliyas ${ }^{1}$, Badil ${ }^{2}$, Alia Nasir ${ }^{3}$, Shaheen Sherali ${ }^{4}$, Imran Khan ${ }^{5}$, Kamran Khan $^{6}$, Fayyaz Hashmi ${ }^{7}$
}

\author{
${ }^{1}$ Nursing Instructor, College of Nursing, Ziauddin University, Karachi \\ ${ }^{2}$ Assistant Professor, Institute of Nursing, Dow University of Health Sciences, Karachi \\ ${ }^{3}$ Associate Professor, College of Nursing, Ziauddin University, Karachi \\ ${ }^{4}$ Nursing Instructor, Liaquat College of Nursing, Liaquat National Hospital. Karachi \\ ${ }^{5,6}$ BS. Nursing Student, College of Nursing, Ziauddin University, Karachi \\ Correspondence: Badil, E mail: badil@duhs.edu.pk
}

\begin{abstract}
Background: Pneumonia is the leading cause of death of children under five years of age.

The considerable number of children having pneumonia has difficulty to reach health services in the appropriate time due to their mother's failure to recognize the seriousness of their infection.

Methods: Present cross-sectional study was performed by using a close-ended, adapted questionnaire comprising of 15 closed-ended items. Data was gathered through a convenient sampling method. The calculated sample size was 120 subjects of the female gender. Written consent was taken from each participant before filling of the questionnaire. Data was entered and analyzed in SPSS version 21.00.

Results: Out of 120 subjects, $59.2 \%$ study participant was illiterate, $51.6 \%$ subjects were in the age group of 31 to 41 years. $15.8 \%$ of women had fair knowledge whereas $55.5 \%$ of women did not have knowledge about pneumonia. And $28.7 \%$ of women they did not know what is pneumonia. $60.8 \%$ of respondents were unable to recognize sign and symptoms of pneumonia. Only $19.2 \%$ of participants know vaccination of pneumonia should be made essential for children.

Conclusion: The study concluded that mother had scanty knowledge of pneumonia its preventive measure, and immunization. The government should also provide awareness through mass media, so that the mortality and morbidity rates can be reduced and many valuable lives can be protected.

Keywords: Pneumonia, contagious, infectious, mothers
\end{abstract}

\section{Introduction}

Pneumonia is the major cause of mortality of children under five years of age across the globe $(1,2)$.It is established by research that pneumonia was responsible of deaths of 920,136 children under the age of five years in 2015 , accounting for $16 \%$ of all deaths of children under five year's old (3). Furthermore, timely and appropriate treatment could save the life of children diagnosed with pneumonia (4). It is evident that pneumonia is a acute respiratory infection. In pneumonia, the alveoli are filled with pus and fluid, which makes difficulty in oxygen intake and cause painful breathing (5). Pneumonia has recognized common infection in children worldwide whereas, it is most prevalent in South Asia and sub-Saharan Africa (6). According to WHO (World Health Organization), in 2016 routine immunization programmed prevented pneumonia in all countries (7). Moreover, substantial number of children having pneumonia could not access health services well at the proper time because their mothers fail to identify the seriousness of their illness (1). It is affirmed by current research that mortality of children can be minimized by identifying the sign and symptoms of the pneumonia by mothers at earliest (8). The WHO and UNICEF (United Nations International Children's Emergency Fund ) have endorsed strengthening family's capability to identify danger signs and swift care seeking as one of the interventions for controlling pneumonia in children under five (9). It is confirmed by recent research that enormous number of children suffering from pneumonia does not receive suitable treatment at health service (10). It is documentary evidence by researches that pneumonia has become the primary reason of mortality in children under age in the developing countries (11). In addition, clinical pneumonia incidence ranked top in South-East Asia (0.36 episodes per child-year), closely followed by Africa ( 0.33 episodes per child-year) and by the Eastern Mediterranean ( 0.28 episodes per child-year), and lowest in the Western Pacific (0.22 episodes per child- 


\title{
MOTHERS KNOWLEDGE RELATED PREVENTIVE MEASURE OF PNEUMONIA IN SLUM COMMUNITY, KARACHI, PAKISTAN
}

\author{
Adeel Eliyas ${ }^{1}$, Badil $^{2}$, Alia Nasir ${ }^{3}$, Shaheen Sherali ${ }^{4}$, Imran Khan ${ }^{5}$, Kamran Khan $^{6}$, Fayyaz Hashmi ${ }^{7}$
}

${ }^{1}$ Nursing Instructor, College of Nursing, Ziauddin University, Karachi

${ }^{2}$ Assistant Professor, Institute of Nursing, Dow University of Health Sciences, Karachi

${ }^{3}$ Associate Professor, College of Nursing, Ziauddin University, Karachi

${ }^{4}$ Nursing Instructor, Liaquat College of Nursing, Liaquat National Hospital. Karachi

${ }^{5,6} \mathrm{BS}$. Nursing Student, College of Nursing, Ziauddin University, Karachi

Correspondence: Badil, E mail: badil@duhs.edu.pk

\begin{abstract}
Background: Pneumonia is the leading cause of death of children under five years of age.

The considerable number of children having pneumonia has difficulty to reach health services in the appropriate time due to their mother's failure to recognize the seriousness of their infection.

Methods: Present cross-sectional study was performed by using a close-ended, adapted questionnaire comprising of 15 closed-ended items. Data was gathered through a convenient sampling method. The calculated sample size was 120 subjects of the female gender. Written consent was taken from each participant before filling of the questionnaire. Data was entered and analyzed in SPSS version 21.00.

Results: Out of 120 subjects, $59.2 \%$ study participant was illiterate, $51.6 \%$ subjects were in the age group of 31 to 41 years. $15.8 \%$ of women had fair knowledge whereas $55.5 \%$ of women did not have knowledge about pneumonia. And $28.7 \%$ of women they did not know what is pneumonia. $60.8 \%$ of respondents were unable to recognize sign and symptoms of pneumonia. Only $19.2 \%$ of participants know vaccination of pneumonia should be made essential for children.

Conclusion: The study concluded that mother had scanty knowledge of pneumonia its preventive measure, and immunization. The government should also provide awareness through mass media, so that the mortality and morbidity rates can be reduced and many valuable lives can be protected.

Keywords: Pneumonia, contagious, infectious, mothers
\end{abstract}

\section{Introduction}

Pneumonia is the major cause of mortality of children under five years of age across the globe $(1,2)$.It is established by research that pneumonia was responsible of deaths of 920,136 children under the age of five years in 2015 , accounting for $16 \%$ of all deaths of children under five year's old (3). Furthermore, timely and appropriate treatment could save the life of children diagnosed with pneumonia (4). It is evident that pneumonia is a acute respiratory infection. In pneumonia, the alveoli are filled with pus and fluid, which makes difficulty in oxygen intake and cause painful breathing (5). Pneumonia has recognized common infection in children worldwide whereas, it is most prevalent in South Asia and sub-Saharan Africa (6). According to WHO (World Health Organization), in 2016 routine immunization programmed prevented pneumonia in all countries (7). Moreover, substantial number of children having pneumonia could not access health services well at the proper time because their mothers fail to identify the seriousness of their illness (1). It is affirmed by current research that mortality of children can be minimized by identifying the sign and symptoms of the pneumonia by mothers at earliest (8). The WHO and UNICEF (United Nations International Children's Emergency Fund ) have endorsed strengthening family's capability to identify danger signs and swift care seeking as one of the interventions for controlling pneumonia in children under five (9). It is confirmed by recent research that enormous number of children suffering from pneumonia does not receive suitable treatment at health service (10). It is documentary evidence by researches that pneumonia has become the primary reason of mortality in children under age in the developing countries (11). In addition, clinical pneumonia incidence ranked top in South-East Asia ( 0.36 episodes per child-year), closely followed by Africa (0.33 episodes per child-year) and by the Eastern Mediterranean (0.28 episodes per child-year), and lowest in the Western Pacific (0.22 episodes per child- 
year) (12). Hence, mother's knowledge may reduce occurrence of pneumonia in children less than five years. The main objective of the present study is to describe the knowledge and preventive measures about pneumonia under five years of age in a slum community of Karachi.

\section{Methodology}

This cross-sectional study was accomplished at Shireen Jinnah Colony, Karachi. The duration of the study was seven months from, May 2017 to December 2017. The females subjects with age more than 20 years old and having children less than five years of age were enrolled for the study. Married women having no children were excluded from the study. Sample was calculated by using OpenEpi version 3.0. The calculated sample was 120 subjects of the female gender. Data were collected through convenient sampling method. The response rate of participation of subjects was $100 \%$. The data was collected by an adopted questionnaire, comprised of 15 questions. 20 minutes provided to participants for the completion of the questionnaire. The questionnaire was translated in the Urdu language. Consent was signed by the participants. While collecting data, respondents who felt difficulty to understand questions and were made understand. The large number was illiterate subjects. Hence, the primary investigator helped to fill out the questionnaire. The participation of the subjects was voluntary. Confidentiality and privacy was maintained throughout the study. Data were analyzed in SPSS version 21.0. Quantitative variables were presented in Mean and Standard deviation and the qualitative variable was presented in frequency and percentages.

\section{Results}

Table 1 reveals the frequencies of demographic characteristics of study participants. Out of 120 subjects, $40.8 \%$ were literate subjects while $59.2 \%$ were illiterate subjects. The participants whose age was between 20 to 30 years were $44.2 \%, 31$ to 41 years were $51.6 \%$ and 42 to 52 years only $4.2 \%$ subjects. As for as language concern, $50 \%$ participants were Urdu speaking and $33.3 \%$ were Sindhi speaking.

Table 1: Frequencies of Demographic Characteristics of study Participant $(\mathrm{N}=120)$

\begin{tabular}{|l|l|l|}
\hline Demographic variable & Frequency (f) & Percentage (\%) \\
\hline $\begin{array}{l}\text { Education level } \\
\text { Literate } \\
\text { Illiterate }\end{array}$ & 49 & $40.8 \%$ \\
& 71 & $59.2 \%$ \\
\hline Age & & \\
$20-30$ & 53 & $44.2 \%$ \\
$31-41$ & 62 & $51.6 \%$ \\
$42-52$ & 05 & $4.2 \%$ \\
\hline Language & & \\
Sindhi & 40 & $33.3 \%$ \\
Urdu & 60 & $50 \%$ \\
Pashto & 06 & $5 \%$ \\
Punjabi & 04 & $3.3 \%$ \\
Others & 10 & $8.3 \%$ \\
\hline
\end{tabular}

Table 2 discloses the mother's knowledge and preventives measures for pneumonia. First of all subjects were asked what do you know that pneumonia is one of the leading causes of deaths globally? For this question, $73.3 \%$ subjects stated that they know it is the leading cause of death while $18.3 \%$ were not agreed and $8.4 \%$ said that we don't know about this fact. With regard to the 2 nd question, is vaccination the most effective way of preventing pneumonia? $63.3 \%$ of respondents reported that immunization is exceptionally compelling in avoiding pneumonia. $24.2 \%$ members stamped their reply with NO. As it were $12.5 \%$ didn't concur with either YES or NO. When the participants were inquired that Can mother's knowledge prevent child from pneumonia?58\% reacted their reply in NO whereas $20 \%$ reacted in YES and only22\% said they don't know. Moving to the next question that was pneumonia is a contagious disease? $50.8 \%$ subjects chosen yes, $22.2 \%$ respondents clicked on No. And $27 \%$ members stamped on don't know. Children will get pneumonia easily if they don't take appropriate Immunization? 59.2\% subjects chosen on YES. 27.5\% selected NO whereas 13.3 preferred on don't know. Under nutrition children are easier to get pneumonia or another severe infectious disease than children who have better nutrition status? $61.7 \%$ respondents reported on YES. $20.8 \%$ stated NO whereas $17.5 \%$ described on don't know. When asked a question that congested houses allow respiratory infection spread easily among family members? $49.2 \%$ of subjects said that congested houses permit respiratory disease spread effortlessly among family individuals, $25.8 \%$ agreed on NO, while $20 \%$ marked on don't know. A cough and cold are typical conditions for children; it will not get worse, even if it is left untreated? Responding to this question, $63.3 \%$ respondents replied that cough and cold are usual conditions for children; it'll not get more unpleasant, indeed on the off chance that it is cleared out untreated?, and $21.7 \%$ participant don't think so, whereas $15 \%$ favored on don't know. Keep household and environment that surrounds it clean will prevent children from getting Pneumonia? $20 \%$ subjects approved that by keeping family and environment neat and clean may prevent children from getting pneumonia, on the other hand, $56.7 \%$ refuted this view and $23.3 \%$ marked on don't know. Providing fresh air regularly to children's room will prevent children from getting Pneumonia? 53.3\% participants believed that by giving fresh air frequently to the children that can prevent the children from pneumonia, but $30 \%$ contradicted and $16.7 \%$ selected on don't know.

Is it better to give children complete immunization to prevent them from pneumonia? Majority of $60.8 \%$ subjects agreed with statement, however, $22.6 \%$ opposed the statement and $16.7 \%$ selected don't know. A cough and fast breathing is the serious sign of pneumonia? $15.8 \%$ respondent selected Yes while $60.8 \%$ reported No and $23.4 \%$ marked on don't know. Running nose and cough only is the serious sign of pneumonia? Respondents which favored Yes are 40.8\% while respondents which not agreed is $39.2 \%$ and which marked on don't know is $20 \%$. Washing your hands is 
the preventive measure of Pneumonia? $45.8 \%$ subjects think that washing hands may prevent from pneumonia, yet, $30 \%$ don't think so and $24.2 \%$ selected don't know. When last question asked from participants that is pneumonia vaccination should be made compulsory for children and adults? 19.2\% respondents reported YES, and $42.5 \%$ nominated on NO, while $38.3 \%$ designated on don't know.

Table 2. Mothers Knowledge and Preventives Measures for Pneumonia ( $N=120)$

\begin{tabular}{|c|c|c|c|}
\hline Statements & Yes & No & $\begin{array}{l}\text { Don't } \\
\text { know }\end{array}$ \\
\hline $\begin{array}{l}\text { 1. Do you know that pneumonia is one of the } \\
\text { leading causes of deaths globally? }\end{array}$ & $73.3 \%$ & $18.3 \%$ & $8.4 \%$ \\
\hline $\begin{array}{l}\text { 2. Is vaccination the most effective way of } \\
\text { preventing pneumonia? }\end{array}$ & $63.3 \%$ & $24.2 \%$ & $12.5 \%$ \\
\hline $\begin{array}{l}\text { 3. Can mother's knowledge prevent child } \\
\text { from pneumonia? }\end{array}$ & $20 \%$ & $58 \%$ & $22 \%$ \\
\hline 4. Is pneumonia a contagious disease? & $50.8 \%$ & $22.2 \%$ & $27 \%$ \\
\hline $\begin{array}{l}\text { 5. Children will get pneumonia easily if they } \\
\text { don't take appropriate Immunization? }\end{array}$ & $59.2 \%$ & $27.5 \%$ & $13.3 \%$ \\
\hline $\begin{array}{l}\text { 6. Does under nutrition children easier to get } \\
\text { pneumonia? }\end{array}$ & $61.7 \%$ & $20.8 \%$ & $17.5 \%$ \\
\hline $\begin{array}{l}\text { 7. Congested houses allow respiratory } \\
\text { infection spread easily among family } \\
\text { members? }\end{array}$ & $49.2 \%$ & $25.8 \%$ & $25 \%$ \\
\hline $\begin{array}{l}\text { 8. Cough and cold are typical conditions for } \\
\text { children; it will not get worse, even if it is } \\
\text { left untreated? }\end{array}$ & $63.3 \%$ & $21.7 \%$ & $15 \%$ \\
\hline $\begin{array}{l}\text { 9. Keep household and environment that } \\
\text { surround it clean will prevent children } \\
\text { from getting pneumonia }\end{array}$ & $20 \%$ & $56.7 \%$ & $23.3 \%$ \\
\hline $\begin{array}{l}\text { 10. Providing fresh air regularly to children's } \\
\text { room will prevent children from getting } \\
\text { Pneumonia? }\end{array}$ & $53.3 \%$ & $30 \%$ & $16.7 \%$ \\
\hline $\begin{array}{l}\text { 11. It's better to give children complete } \\
\text { immunization to prevent th em from } \\
\text { pneumonia? }\end{array}$ & $60.8 \%$ & $22.6 \%$ & $16.6 \%$ \\
\hline $\begin{array}{l}\text { 12. Cough and fast breathing is serious sign of } \\
\text { pneumonia? }\end{array}$ & $15.8 \%$ & $60.8 \%$ & $23.4 \%$ \\
\hline $\begin{array}{l}\text { 13. Running nose and cough only is serious } \\
\text { sign of pneumonia? }\end{array}$ & $40.8 \%$ & $39.2 \%$ & $20 \%$ \\
\hline $\begin{array}{l}\text { 14. Washing your hands is the preventive } \\
\text { measure of Pneumonia? }\end{array}$ & $45.8 \%$ & $30 \%$ & $24.2 \%$ \\
\hline $\begin{array}{l}\text { 15. Pneumonia vaccination should be made } \\
\text { compulsory for Children and adults? }\end{array}$ & $19.2 \%$ & $42.5 \%$ & $38.3 \%$ \\
\hline
\end{tabular}

\section{Discussion}

Pneumonia is an infectious disease which can lead to deaths in children under five years of age. Mother's knowledge is very much essential to prevent and, take care of pneumonia, as she is more close to her children, she could be the first to notice these changes in a child's health. It can solely be possible when mothers may aware of pneumonia, its signs and symptoms, and when to seek medical help. Internationally, in many countries, different studies have been carried out, and several robust steps have been taken to spread awareness. The present study only focused on assessing mothers' knowledge in pertinent to pneumonia and its preventive measures. Majority of mothers belong to the age group of 31 to 41 years $(51.6 \%)$, whereas other studies conducted in India were of 25-31 years (45.4\%) (13) both this study shows age does not matter in increasing mother knowledge about pneumonia, whereas study conducted in Iran contradict with this finding they have revealed mother age and level of knowledge has association with each other (14). As far as the education level of a mother is concerned, our study participants were more literate $40.8 \%$ as compared to other study has only $32.6 \%$ literacy level (13). Although we did not compare the association of mothers' education level with their knowledge, another study has shown that there is the positive association between them (15). The current study found that more than $50 \%$ mothers were able to identify the cause and related factors, which contribute towards pneumonia. And, this became an important finding of this study, as in other study affirmed only $21 \%$ (6). Further exploring about signs and symptoms of the disease, $60.8 \%$ of the participants were incapable to recognize accurate signs and symptoms. This result was much higher than other study reported $41.3 \%$ (13). This result shows that the majority of the mothers are not aware of the signs and symptoms of pneumonia, and thus this can be the reason why they do not bring their child early to the hospital for treatment. Whereas in other study majority of mothers were able to correctly pick signs and symptoms of pneumonia (16 ) Only $20 \%$ mothers indicated that keeping clean environment will prevent children from getting pneumonia whereas this result was much lower as compared to the study conducted in Pakistan on acute respiratory infection in children less than of five years, reported $81 \%$ (17).Few study has been found that Pneumonia is more associate with malnourished children (18). We further investigated awareness about vaccination as a preventive measure and only $19.2 \%$ of respondents recognized vaccination of pneumonia should be made compulsory for children. According to WHO report 2010 there is an extensive need for effective interventions program in all parts of the world in order to bring down mortality and morbidity rates due to pneumonia (19).

\section{Conclusion}

It is concluded that mother had poor knowledge about pneumonia and their preventive measures. Mothers had poor knowledge about immunization of pneumonia, their sign and symptoms such as a cough and breathing problems, an environment which effects on pneumonia.

\section{References}

1. Abusaad FE, Hashem SF. Mothers learning needs assessment regarding pneumonia among children less than five years at Saudi Arabia. Iran J Nurs Midwifery Res. 2014; 3(5):85-93.

2. Abass N, El Aziz MA, Hal N, et al. Effect of structured patient education program on the knowledge level of mothers regarding childhood gastroenteritis and pneumonia at El-Raml Pediatric Hospital. Curr Pediatr Res. 2017; 21(3): 368-374.

3. WHO. (2016). Pneumonia. Media Centre, 5062 . [ I n t e r n e t]. W e b s i t e : http://www.who.int/mediacentre/factsheets/fs33 1/en/.Retrieved on February 12, 2016. 
4. Bhutta ZA, Das JK, Walker N, Rizvi A, Campbell $\mathrm{H}$, Rudan I, et al. Interventions to address deaths from childhood pneumonia and diarrhea equitably: what works and at what cost? Lancet. 2013; 381(9875):1417-29.

5. Janssens JP, Krause KH. Pneumonia in the very old. Lancet Infect Dis. 2004; 4(2):112-24.

6. Siswanto, E., Bhuiyan, S. U., \& Chompikul, J. Knowledge and Perception of Pneumonia Disease among Mothers of Children under Five Years attending Nakhon Pathom General Hospital, Thailand. J Pub Health Dev, 2007; 5(2): 43-54.

7. WHO. Pneumonia. Media Centre, 2016; 50-62. [ I n t e rne t]. W e b s i t e : http://www.who.int/mediacentre/factsheets/fs33 1/en/. Retrieved on February 25, 2016.

8. Agarwal M, Bajpai P. Perception about childhood pneumonia among caregivers attending immunization clinics of tertiary care hospital in Lucknow City. Int J Pharm Sci Res. 2015; 4(4): 127-30.

9. Ndu IK, Ekwochi U, Osuorah CD et al. Danger signs of childhood pneumonia: caregiver awareness and care seeking behavior in a developing country. Int J Pediatr. 2015; 15(1): 17.

10. Theodoratou, E., Jilaihawi, S. A., Woodward, F., Furguson, J., Jhass, A., Balliet, M., et al. The effect of case management on childhood pneumonia mortality in developing countries. Int J Epidemiol. 2010. 40(2): 155-171.

11. Aftab S, Ejaz I, Waqar U, Khan HI, Hanif A, Usman A, Mushtaq A, Nadeem IM, Asmara HS, Baig AA. Risk Factors for Childhood Pneumonia in North Eastern Pakistan: A Case-Control Study. MJPCH. 2017; 22(2):26-34.

12. W H O [ I n t e rne t]. We b s it e : http://www.who.int/bulletin/volumes/86/5/07048769/en/. Retrieved on March 20, 2016.

13. Pradhan SM, Rao AP, Pattanshetty SM, Nilima AR. Knowledge and perception regarding childhood pneumonia among mothers of underfive children in rural areas of Udupi Taluk, Karnataka: A cross-sectional study. Indian J health Sci. 2016; 9:35-9.

14. Farhad J, Malihe A, Fatemeh A, Mahmood S. The knowledge, attitude and practice of mothers regarding acute respiratory infections in children, Iran. Biosciences Biotechnology Research Asia 2014; 11:343-8.

15. Ekure EN, Esezobor Cl, Balogun MR, MukhtarYola M, Ojo OO, Emodi JJ, et al. Mothers and childhood pneumonia: What should the focus of public campaign be?. Niger J Paed. 2013; 40:249.

16. Athumani J. Knowledge, Attitudes and Practices of mothers on symptoms and signs of integrated management of Childhood Illnesses (IMCI) strategy at Buguruni Reproductive and Child Health clinics in Dar es Salaam. Dar Es Salaam Medical Students' Journal. 2008; 15(1):4-8.

17. Bham SQ, Saeed F, Shah MA. Knowledge, Attitude and Practice of mothers on acute respiratory infection in children under five years. Pak J Med Sci. 2016; 32(6):1557-61.

18. Nannan N, Norman R, Hendricks M, Dhansay MA, Bradshaw D. Estimating the burden of disease attributable to childhood and maternal undernutrition in South Africa in 2000. S Afr Med J. 2007; 97(8):733-9.

19. Nga Tong. A Public Health Approach to Innovation. 2003. [Interenet]. Website: http://apps.who.int/medicinedocs/documents/s 20269en/s20269en. Retrieved on July 15, 2018. 